\title{
RECURSOS HUMANOS E MUNICIPALIZAÇÃO: NOTAS SOBRE O PANORAMA LEGAL
}

\author{
Ana Maria Cavalcanti Simioni * \\ Neusa Atique**
}

RESUMO: O presente artigo tem por finalidade abordar o processo de municipalização no Estado de São Paulo no tocante à questăo de Recursos Humanos. O estudo será desenvolvido de dois pontos de vista: a) do ângulo histórico, isto é, de como a área de Recursos Humanos integra-se ao processo do desenvolvimento das políticas nacionais de saúde; b) e do ângulo da construção do Sistema Único de Saúde que se realiza no cotidiano, tendo como sujeitos as instituições Federais, Estaduais e Municipais e como contexto o Estado de Såo Paulo.

\section{HISTÓRICO}

Antes de abordarmos propriamente nosso tema, é importante lembrar que ao discorrermos sobre o problema historicamente, a sucessão de leis e decretos pode nos fazer perder a dimensão social do processo de municipalização, causando-nos muitas vezes a impressão das leis terem vida

* Diretora Técnica de Divisão do Grupo Técnico de Treinamento e Desenvolvimento de Recursos Humanos da Coordenadoria de Recursos Humanos de Secretaria de Estado da Saúde de São Paulo

* * Diretora Técnica de Departamento do Centro de Legislação de Pessoal da Coordenadoria de Recursos Humanos da Secretaria de Estado da Saúde de São Paulo. 
própria. Por isso devemos estar atentos para o fato de que a municipalização não é apenas uma política de governo, mas um movimento social que permeia as ações dos governos, nas três esferas de sua atuação.

O levantamento histórico da legislação referente a área de Recursos Humanos nos mostra que a referida legislação acompanha, em geral, a concepção do modelo de saúde vigente: a área de Recursos Humanos (R.H.) é sempre o veículo de concretização das políticas de saúde em um dado momento, lugar e época (1).

Até 1980, a saúde no Brasil obedecia à lógica da dicotomia entre serviços coletivos, de caráter preventivo, e individuais, de caráter curativo, cabendo ao Estado os primeiros e ao setor privado a assistência médica propriamente dita.

Nesta ocasião, o sistema de saúde como um todo tinha como característica a centralização tanto de recursos como de decisões. A política de Recursos Humanos para o período também acompanhava este caráter centralizador, sendo a contratação, seleção, treinamento, desenvolvimento e avaliação de pessoal, tanto na esfera Federal, quanto na Estadual ou Municipal, realizada por órgãos da administração centralizada.

Vale lembrar que nesta ocasião (década 70-80) começa a aumentar a participação dos municípios no setor saúde. Estes dão início a expansão dos seus serviços com a conseqüente contratação de profissionais para a área da saúde. A característica do processo de municipalização no período, para o Estado de São Paulo, é que estes serviços eram autônomos não dependendo de qualquer convênio. 
No início da década de 80 a crise econômica geral do país atinge a área da saúde e o então modelo de estatização privatizante(2) entra também em crise financeira. Surgem, então, sucessivamente, o plano CONASP, o PREVSAÚDE e o programa das Ações Integradas de Saúde (AIS).

Em São Paulo, as AIS tiveram seu grande momento de implantação em 1984 e representaram importante precursor do processo de municipalização. Como os municípios já haviam iniciado, na década anterior, uma expansão de serviços e de recursos humanos, com as AIS houve, através de convênios estabelecidos com o INAMPS, a possibilidade de acelerar o processo. Neste momento o INAMPS deixa de comprar serviços do setor privado passando a fazêlo através do setor público, comprando-os do município. A partir de 1984 ocorre a grande expansão da assistência médica no estado.

Começa a amadurecer, aí, a reforma sanitária, que propõe, sistemática e persistentemente, para a área de Recursos Humanos, as seguintes diretrizes:

- eliminação da dupla militância;

- dedicação exclusiva para funções de chefias;

- isonomia salarial entre as esferas federal, estadual e municipal;

- estabelecimento de plano de carreiras, cargos e salários;

- desenvolvimento de programas de educação e formação de recursos humanos para o sistema de saúde (3). 
O objetivo subjacente a estas diretrizes era a fixação e valorização dos Recursos Humanos do Setor Saúde.

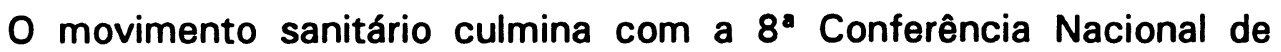
Saúde em 1986, cujo relatório final propõe uma mudança radical do sistema. A saúde passa a ser vista como um direito da cidadania e um dever do estado.

A nova concepção tem como conseqüência a mudança do perfil de atendimentos, deixando as unidades municipalizadas de ser postos de puericultura passando a incorporar a assistência médica integral. A grande expansão de Recursos Humanos na rede municipal se faz, nesta época, às custas de incorporação de assistência médica.

Para atender ao novo modelo que está sendo proposto, a Secretaria Estadual de São Paulo, em 1986, reorganiza seus serviços através de reforma administrativa. As estruturas verticais são substituídas por estruturas regionalizadas, os Escritórios Regionais de Saúde(ERSAs). Foram criados para o Estado de São Paulo 62 ERSAs (hoje, em 1993, existem 65).

A área de Recursos Humanos acompanha esta descentralização sendo também regionalizada.

Foi criada, em cada ERSA, a diretoria de grupo técnico de recursos humanos, com chefia de pessoal. Descentraliza-se desta maneira a área de Recursos Humanos, que passa a selecionar, treinar, contratar e administrar regionalmente os recursos humanos da área da saúde.

No final da década de 80 é celebrado o convênio SUDS (em 22/06/87), fundado em duas estratégias básicas: a estadualização do INAMPS e a municipalização dos serviços de saúde. A municipalização foi possível posto já 
haver um processo anterior com as AIS e com o convênio dos municípios carentes e, principalmente, porque o número de servidores municipais havia crescido muito no período de 1981 a 1987, configurando um estoque prévio de Recursos Humanos que, certamente, muito contribuiu para a viabilização do processo.

Dados recentes do Ministério da Saúde (2) indicam mudanças fundamentais na área de Recursos Humanos no período de 1981 a 1982:

$\left.1^{\circ}\right)$ A expansão do número de postos de trabalho do setor público, passando em 1987 para $55,1 \%$ (anteriormente a maior parte dos postos pertencia ao setor privado).

$\left.2^{\circ}\right)$ Aumento significativo de Recursos Humanos nos setores estaduais e municipais (O Estado aumenta em torno de $70 \%$ e o Município 121\%) enquanto há uma diminuição do pessoal federal.

$\left.3^{\circ}\right)$ Diminuição do pessoal no setor privado, tanto lucrativo como não lucrativo.

O convênio SUDS acima referido estabeleceu alguns compromissos no que tange à questão de Recursos Humanos:

Na sua cláusula III item 1, assegura aos funcionários e servidores a preservação do seu vínculo funcional ou trabalhista com o seu órgão de origem, bem como, os direitos e vantagens adquiridas e outras que vierem a ser estabelecidas pelos quadros de pessoal que o funcionário/servidor se integre.

No seu item 2, assegura a aplicação da equivalência salarial e tempo integral geográfico. 
Em seu item 3, assegura o repasse de recursos para o pagamento da equivalência salarial.

Em 30/06/87 é publicada resolução CIS/SP atribuindo ao grupo técnico "Sistema Integrado de Recursos Humanos" competências para:

- estudar o quadro da Secretaria Estadual e do INAMPS

- elaborar plano de equivalência salarial, bem como programa de formação e treinamento

- elaborar modelo de carreiras integradas garantindo direitos adquiridos.

Em 01/10/87 o CIS/SP, em sua resolução 41/87 institui a equivalência salarial entre os funcionários (servidores da Secretaria Estadual da Saúde e os do INAMPS).

Em 30/06/87 é assinado o Decreto 27.140 no qual o Governador do Estado de São Paulo autoriza o convênio de municipalização dos serviços de saúde.

Em 20/07/87 é assinado o Decreto $n^{\circ} 94.657$ no qual o Presidente da República cria o SUDS.

Isto mostra que São Paulo assinou o convênio SUDS antes do decreto federal.

O decreto de municipalização (27.140) estabelece diretrizes para os Recursos Humanos. Na cláusula lla, que diz das obrigações da Secretaria, verificamos, no artigo 10, que a esta compete: colocar à disposição do município, mediante afastamento, os funcionários e servidores em exercício nas 
unidades locais, respeitando-se todos os direitos e vantagens a eles assegurados na legislação estadual específica e na CLT. Reserva-se ao município, com anuência da CIMS, o direito de não se interessar por servidor do estado. Em seu artigo 11, diz o decreto dos recursos orçamentários e financeiros que seriam assegurados pela Secretaria da Saúde para reposição de pessoal colocado à disposição do município. Em seu artigo 19 define como competência da CRIS, CIMS e CIS, entre outras, o remanejamento de pessoal em função da integração e racionalização da oferta de serviços à população.

Ficou pelo mesmo convênio definido como obrigação do município:

- proceder a reposição do pessoal municipalizado;

- treinar pessoal, em conjunto com os ERSAs.

A partir deste momento os municípios passam a gerenciar seus sistemas locais de saúde. São Paulo passa então a viver uma grave crise no que tange aos Recursos Humanos da saúde.

A situação de R.H. ficou de difícil gerenciamento porque passaram a conviver em uma mesma unidade ou em um mesmo município, funcionários municipais, estaduais e federais, com diferentes formas contratuais e, portanto, jornadas, salários e direitos diferentes.

A disparidade salarial entre funcionários estaduais e federais surge quando, em 23 de junho de 88, na nova minuta do convênio SUDS, a União silencia a respeito dos recursos para a equivalência salarial. Assim, deixa de existir, na prática, a isonomia salarial entre as três esferas a que nos referimos acima. 
O convênio de municipalização, por sua vez, em momento algum, estabeleceu a isonomia ou a equivalência entre funcionários de esferas diferentes: o pagamento da isonomia, desde a assinatura do convênio, ficou a cargo da cada município; o que, neste convênio, ficou colocado foi, somente, a garantia do repasse de recursos em caso de necessidade de reposição de pessoal municipalizado, fato também silenciado, posteriormente, no Decreto 28410/88 no qual se revoga o Decreto $27140 / 87$, nada se falando a respeito da garantia do referido repasse.

Em outubro de 1988 é promulgada a nova constituição e em 09 de setembro de 1990 é sancionada a lei orgânica. Fica criado o Sistema Único de Saúde (Lei Federal 8080/90).

No que se refere à área de R.H, a lei orgânica regulamentando o SUS, não acrescenta novos princípios ou diretrizes, tendo sido vetado pelo Presidente - Artigo 27, que previa a instituição, em cada esfera, do plano de cargos e salários e a carreira do pessoal SUS. Foi, também, vetado o inciso III do mesmo artigo, que previa a fixação de pisos nacionais de salários por categoria profissional e a complementação dos estados e municípios de forma atender as diferenças regionais.

Em 28/1/90 a Lei 8.142 estabelece como pré-requisito para o repasse de recursos financeiros para Estados e Municípios a criação de comissão para a elaboração de plano de cargos e salários e sua implantação em dois anos. 


\section{SITUAÇÃO ATUAL}

Diversos encontros realizados em São Paulo avaliaram positivamente o processo de municipalização.

A proximidade que o gestor da esfera municipal mantém com os serviços e a clientela tem feito com que as ações de saúde atendam melhor às necessidades do cidadão.

Em que pese estas avaliações, não podemos deixar de frisar que a questão de Recursos Humanos para o SUS não tem sido tratada com a importância devida.

Hoje, a crise do sistema é acompanhada pela crise da área de Recursos Humanos: todos sabemos que o SUS poderia até funcionar sem grandes equipamentos ou com poucos recursos financeiros, mas, certamente, uma forte desagregação junto a seus Recursos Humanos seria fatal para 0 sistema.

Podemos relacionar vários ingredientes que caracterizam esta crise.

Como vimos no histórico exposto anteriormente, a lei é particularmente concisa e parcimoniosa no que se refere aos Recursos Humanos.

Notamos também que não há, no arcabouço legal, intenção definida de resolver a crise gerencial decorrente da coexistência de funcionários oriundos das três esferas. Muito pelo contrário, a análise nos faz supor que esta preocupação não é, em momento algum, de relevância para o legislador. Assim, notamos que o convênio SUDS é assinado em São Paulo em 22 de junho de 87 
com o compromisso de assegurar o repasse de recursos para o pagamento de equivalência salarial, compromisso este que vimos cair por terra posteriormente.

Verificamos, também, que o recolhimento das funções de confiança bem como o afastamento dos servidores do INAMPS só ocorrem em dezembro de 1988, portanto, um ano e meio após a assinatura do convênio. Isto, em termos práticos, significou que o gestor conviveu por um longo período, em unidades sob seu gerenciamento, com chefias e funcionários de outra esfera, percebendo, ademais, salários distintos e realizando jornadas de trabalho díspares.

Situação mais grave ainda ocorre hoje nas unidades municipalizadas. A Secretaria Estadual de Saúde assinou o decreto de municipalização em junho de 1987 colocando os Recursos Humanos à disposição do município. Porém, somente em maio de 1990, publica a Resolução 126, que contém os primeiros procedimentos a respeito da administração de Recursos Humanos municipalizados. Vale notar, ademais, que a referida Resolução é de caráter transitório, pois mantém os gerentes do Estado, sendo impedida em sua vacância nova designação. Assim, de 1987 a 1993, os gerentes da estrutura estadual permaneceram nas unidades municipalizadas.

A despeito da Resolução 126 impedir a contratação de servidores e a classificação dos mesmos em unidades municipalizadas, diversos expedientes tem sido usados para contornar este problema, como a contratação para unidades do estado e afastamento posterior para as prefeituras. Tanto a manutenção das chefias como a "contratação" de servidores para o município são decorrentes da "carência" de recursos financeiros. 
É importante também lembrar que na capital de São Paulo, a municipalização é ainda bastante incipiente, com poucas unidades sob a gestão municipal. Com efeito, na capital, há em torno de 30.000 funcionários a serem municipalizados; ao que parece, o processo deve ser acelerado ainda este ano de 1993.

A este respeito, o gráfico 1 nos mostra para 1992, que $61 \%$ dos funcionários da Secretaria Estadual de Saúde encontram-se vinculados à Coordenação da Região de Saúde 1 - CRS1, que corresponde aos ERSAs de 1 a 15 , situados na região da Grande São Paulo.

\section{GRÁFICO 1 - No de funcionários por Coordenação de Região de Saúde (CRS) da Secretaria de Estado da Saúde de São Paulo, 1992}

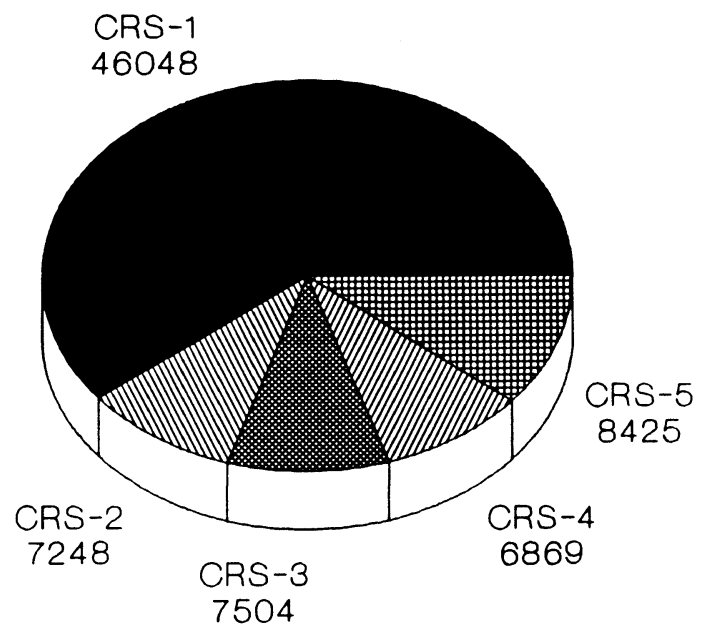

FONTE: CRH - SES 
No que toca aos ERSAS da capital (de 1 a 8), a maioria ainda não municipalizados, verificamos (gráfico 2 ) que absorvem $67 \%$ dos funcionários da CRS1.

\section{GRÁFICO 2 - No de funcionários da Coordenação da Região de Saúde 1 (Grande São Paulo), 1992}

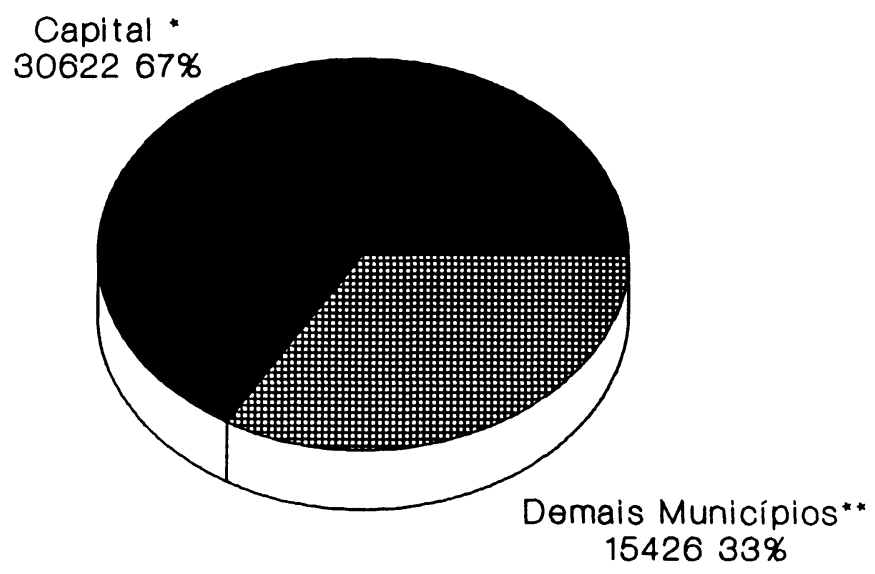

FONTE: CRH - SES

NOTA: * ERSA 1 a 8 (Capital)

* * ERSA 9 a 15 (Demais municípios da G.S.Paulo 
Notamos também (gráfico 3) que, do total de funcionários estaduais, $50 \%$ são estatutários, 33\% CLT 16\% funcionários do INAMPS "estadualizados".

\section{GRÁFICO 3 - Número de funcionários, segundo regime de trabalho, da S.E.S. do Estado de São Paulo, 1992}

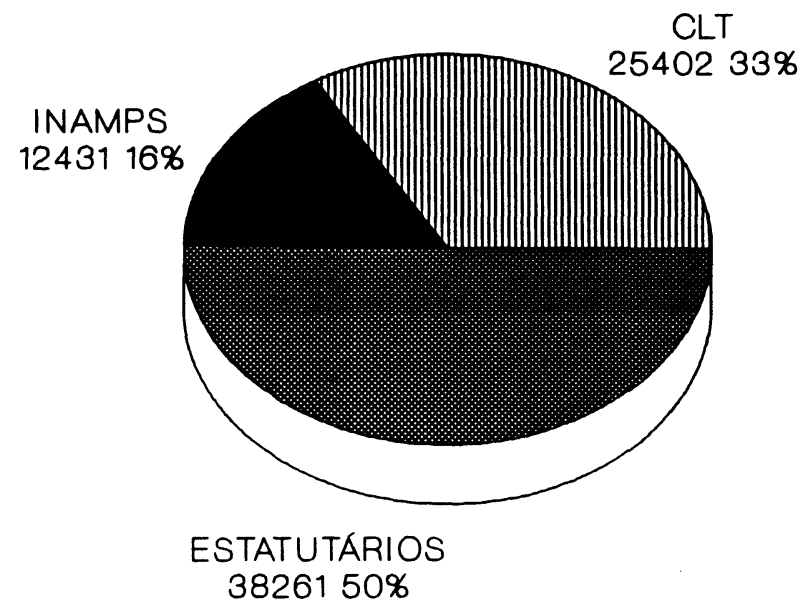

FONTE: CRH - SES

Esta situação inverte-se na Coordenação de Saúde 1 (região metropolitana), onde o percentual de CLT sobe para $45 \%$ dos funcionários (gráfico 4). 


\section{GRÁFICO 4 - Número de funcionários, segundo regime de trabalho, da Coordenação de Região de Saúde - 1 da S.E.S. (Grande São Paulo), 1992}

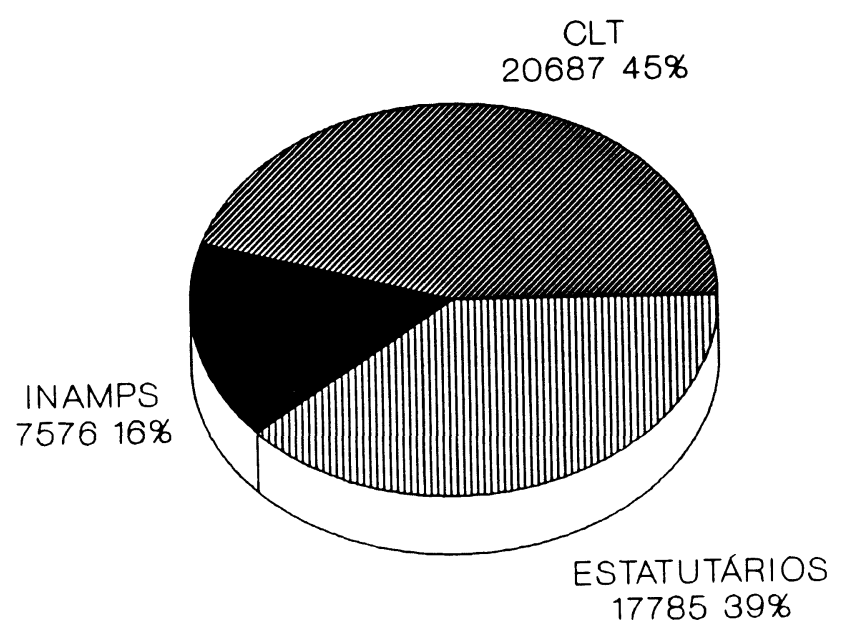

FONTE: CRH - SES

No gráfico 5 notamos que a região correspondente à CRS-1 (região metropolitana) é a mais populosa, com $52 \%$ da população do Estado. Com relação à distribuição percentual da população e funcionários da SES segundo as coordenações regionais de saúde, verifica-se que apenas na CRS-1 (região metropolitana) há proporcionalmente mais funcionários. 


\section{GRÁfICO 5 - Porcentagem de população e de funcionários segundo Coordenaçăo de Região de Saúde}

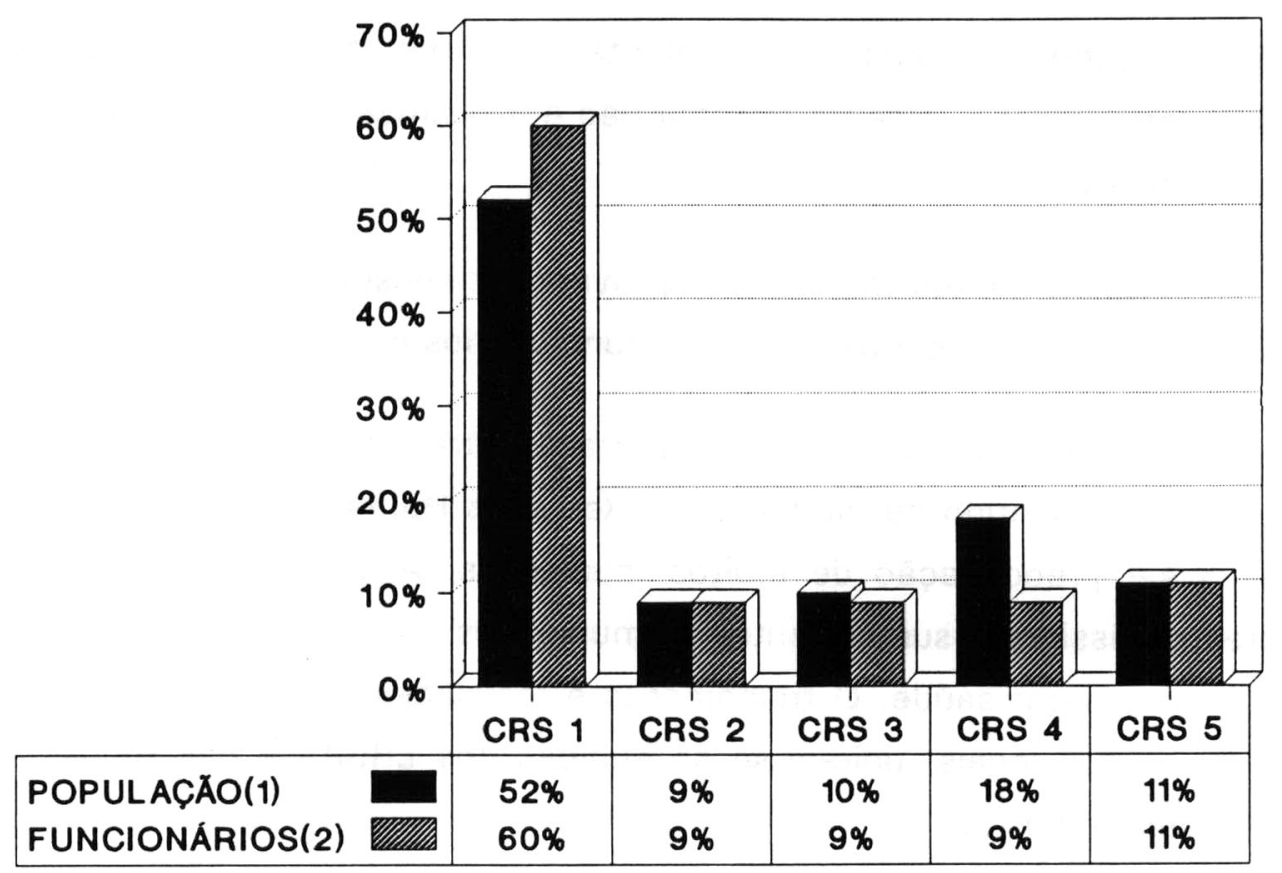

FONTE: (1) SEADE - 1990

(2) CRH-SES - 1992

Estes dados demonstram que a municipalização da Capital é um processo que, pela sua magnitude, se transforma em um capítulo à parte em todo o processo de municipalização.

A falta de repasse de recursos tem também, em muitos municípios, impedido o pagamento da equivalência salarial entre os servidores gerando uma crise gerencial das mais graves. 0 mesmo podemos dizer em relação a fixação 
dos funcionários junto à esfera municipal. Muitos funcionários têm sido devolvidos por motivos não técnicos mas políticos.

Hoje, é este o panorama gerencial para o estado. Tal panorama, a despeito de configurar uma crise evidente não deve, segundo cremos, levar a posições derrotistas; a crise no sistema não é disruptiva mas dialética, levando o SUS a alguns avanços.

Assim, muitos municípios aprovaram dispositivos legais a fim de que a equivalência salarial seja paga para os funcionários municipalizados.

Também o processo de contratação através de seleção com técnicas aprimoradas no sentido de captação de Recursos Humanos de melhor qualidade passou a ser preocupação de muitos municípios. A competição em busca de melhores profissionais surgida entre os municípios tem levado a um aumento de salário para o setor saúde. O treinamento e reciclagem para o pessoal SUS tem feito, em muitos locais, unirem-se as equipes dos ERSAs e dos municípios de uma mesma região.

Além disso, a pressão da municipalização fez com que a Secretaria Estadual de Saúde revisse sua atuação junto a área de Recursos Humanos. Hoje já se tem como proposta a reciclagem de seus gerentes a fim de que possam implementar sua função de assessoria, normatização e coordenação junto aos municípios.

Ao mesmo tempo, esta mesma Secretaria hoje prepara a revisão da Resolução 126. É proposta de seus gerentes a cessação das designações em funções em pró-labore. Isto significa a passagem efetiva da gerência das unidades municipalizadas para a esfera municipal, cabendo ao município a 
escolha do gestor que the convier. Ao mesmo tempo está sendo estudado o critério para fixação dos servidores municipalizados junto as prefeituras de forma a garantir o processo de municipalização.

Este desdobramento do processo de municipalização no Estado de São Paulo, do ângulo das suas implicações legais, indica o seu ritmo e, segundo pensamos, sugere chances reais de implementação do processo, na dependência de se poder controlar interferências disruptivas e desagregadoras de fatores contextuais de natureza macrossocial e político-institucional.

\section{REFERÊNCIAS BIBLIOGRÁFICAS}

1. CONFERÉNCIA ESTADUAL DE SAÚDE, 1*, São Paulo. Relatório: sintese de recursos humanos. São Paulo, Secretaria de Estado da Saúde, 1991.

2. SECRETARIA DE ESTADO DA SAÚDE. Coordenadoria de Recursos Humanos. Municipalização e recursos humanos. São Paulo, 1993.

3. SIMIONI, A.M.C et al O PGI: análise da eficácia de um estímulo financeiro como instrumento de ação gerencial. Secretaria de Estado da Saúde de São Paulo/Faculdade de Saúde Pública da USP/Instituto de Saúde/Cadais. São Paulo, 1991. 